\title{
RESENHA
}

GUÉRIN, Daniel. Fascismo e Grande Capital. Campinas: Editora da Unicamp, 2021.

POULANTZAS, Nicos. Fascismo e Ditadura. Florianópolis: Editora Enunciado, 2021.

Angelita Matos Souza

Instituto de Geociências e Ciências Exatas (IGCE), UNESP angelitams2010@gmail.com

\section{FASCISMO NO SÉCULO XXI?}

Em 2021, duas obras fundamentais para se entender o fenômeno do fascismo foram lançadas no Brasil: Fascismo e grande capital, de Daniel Guérin, publicada pela primeira vez no país, pela Editora da Unicamp; e Fascismo e ditadura, de Nicos Poulantzas, uma reedição muito cuidadosa da Editora Enunciado. São obras sobre o fascismo na Itália e Alemanha, mas o que faz dos dois estudos leituras obrigatórias para se entender o fenômeno é a dimensão trans-histórica que, infelizmente, permita responder positivamente à pergunta: Seria possível falar em fascismo no século XXI?

A obra de Guérin, cuja primeira edição, em francês, é de 1936, completada e reeditada em 1945, concentra-se nos aspectos em comum do fascismo na Itália, país de origem do movimento, e na Alemanha, sem deixar de apontar diferenças. A ideia principal é a de que a origem do fascismo deve ser buscada na própria dinâmica de funcionamento do capitalismo, nas suas crises, neste sentido não seria um fenômeno datado, e sim uma das formas que o capitalismo sempre pode assumir, por toda parte. E uma tese singulariza a análise: o fascismo não deve ser compreendido como resposta à luta de classes, não existia uma situação propriamente revolucionária nos dois países, o que havia era descontentamento forte, da parte de capitalistas, com relação a direitos conquistados pelos trabalhadores após a Primeira Guerra Mundial.

A análise inicia pela fase da ascensão do fascismo, discorrendo sobre o apoio de capitalistas às milícias fascistas, e aponta diferenças político-ideológicas entre eles, por setor de atividade ou dimensão do capital. Também são analisados os aspectos doutrinários-ideológicos, a ascensão e queda da plebe que fornece a base de apoio de massa (com a negação camuflada de suas demandas), 
a situação do proletariado e dos camponeses. Os capítulos sobre o fascismo no poder, analisam as políticas econômica e agrária, ao encontro da monopolização da economia, e o papel do Estado, as contradições envolvidas, o dissenso em conformação no bloco dominante. A organização dos capítulos orientada por fases, das movimentações iniciais ao fascismo no poder, facilita a compreensão do fenômeno e dos acontecimentos narrados.

O título em português é igual ao em francês, Fascisme et grand capital, e indica o centro da análise: a relação entre fascismo e grande capital, em especial o apoio de grandes capitalistas ligados à indústria de bens de capital e de base e dos banqueiros associados aos interesses desse setor. Os representantes da indústria de bens de consumo seriam algo reticentes ao fascismo, mas o grande capital em geral teria apoiado e sido beneficiado pelo regime, na medida em que o fascismo no poder intensificaria a exploração das classes dominadas, nas cidades e no campo (rebaixamento dos salários, repressão dos sindicatos independentes, de qualquer tentativa de mobilização política autônoma, não cumprimentos das promessas de distribuição de terras, do controle corporativista dos meios de produção etc.).

Basicamente, a obra procura demonstrar que o fascismo se consolidou como ditadura do grande capital, negando os traços discursivos anticapitalistas da fase de ascensão. Os mais prejudicados foram o proletariado, urbano e rural, e o campesinato. Além disso, a análise da política econômica e da política agrária demonstra como o fascismo favoreceu a monopolização da economia, na contramão de expectativas das camadas intermediárias (pequena burguesia), cooptadas pela demagogia fascista e base social de apoio à ascensão do fascismo. Para o autor, este seria um fenômeno que decolou sustentado pelo apoio da pequena burguesia, mas no poder teria realizado os interesses dos representantes do grande capital.

Do ponto de vista político-ideológico, o estudo sublinha a natureza reacionária do fascismo, contrária à razão, ao livre pensar, centrada na figura do líder providencial encarado como mito, em uma espécie de religião. O culto ao mito estaria entrelaçado com o culto à pátria, no qual o chefe desponta como a encarnação da nação: adorar ao mito providencial seria servir à pátria e servir à pátria servir ao chefe. Guérin expõe todos os elementos desse cimento ideológico e o papel da propaganda intensa, baseada em frases curtas e simplórias, de fácil memorização. Ademais, um componente importante na armação ideológica seria justamente o desprezo pelo conhecimento científico-intelectual, pela razão, pela alta cultura. 
A análise é rica ao abordar os equívocos do campo progressista diante do fascismo em ascensão; e ao discorrer sobre a fase de ascensão do fascismo sublinhando a repreensão estatal de baixa intensidade às atividades das milícias (da parte da Magistratura e das Armas). Outra dimensão interessante é a exposição sobre como, uma vez alcançado o poder, os partidos fascistas nos dois países foram domesticados pelo Estado, notadamente, as milícias pelas Forças Armadas.

Entretanto, à medida que o Estado avançava sobre a economia, em um sentido cada vez mais de "economia de guerra", a despeito da demanda estatal gerada, o dissenso foi se instalando entre capitalistas insatisfeitos com as crescentes restrições ao "livre comércio" e com as dificuldades impostas às relações internacionais. A cisão no interior do bloco dominante, refletida nas Forças Armadas e segmentos do Estado, seria um indicativo de que o fascismo estaria com dias contados, inclusive e sobretudo em função da reação das demais potências. A guerra mundial acentuou a cisão, devido à imposição de dificuldades político-econômicas crescentes.

Em síntese, relacionamos acima os aspectos em comum do fascismo na Itália e Alemanha, mas a análise é atenta também às diferenças. O livro é um clássico de fácil compreensão, com ensinamentos que interessam à luta política. A publicação da obra no Brasil veio em boa hora, a compreensão sobre o que foi o fascismo na Itália e na Alemanha deve ser permanente e, na conjuntura atual, faz-se urgente. A obra de Guérin desmistifica crenças a respeito, elucida processos políticos amplamente passíveis de repetição e sua publicação em português propiciaria enorme contribuição aos estudos sobre o fenômeno do fascismo no século XX e sobre as movimentações de extrema direita atuais, assim como é valorosa na luta contra o fascismo, à atuação política democrática.

Para encerrar, vale insistir em um diferencial da análise de Guérin: a perspectiva de classe, com destaque para a relação entre fascismo, pequena burguesia e grande capital, sem descurar das diferenças entre os capitalistas, segundo o ramo de atividade, a dimensão do capital, as relações com o mercado mundial. Isto é, a classe capitalista não é abordada como um todo único e homogêneo e seu fracionamento faz diferença nos níveis de adesão ao regime fascista e na conformação de dissensos que contribuirão para sua derrota. Além disso, o fascismo não é concebido como um fenômeno datado e excepcional, ao contrário, seria um dos modos de ser do capitalismo, passível de repetição, inclusive porque engendrado pelo próprio capitalismo e suas crises. Tese que aparece em outros autores (como Poulantzas), contudo, Guérin escreveu bem 
antes, e antecipa a compreensão do fenômeno como algo que pode se repetir, não sendo específico de capitalismos tardios ou uma resposta à luta de classes revolucionária. Cabe ainda registrar os apontamentos sobre o Estado, sobre como a esfera estatal domesticou o fascismo como movimento social (burocratizando-o). Finalmente, a dimensão ideológica-doutrinária é analisada exaustivamente, sendo assustadoramente atual.

Sobre Fascismo e ditadura, obra publicada pela primeira vez na França em 1970, destacaremos a visão do autor sobre o Estado, uma vez que do ponto de vista da luta política, a análise de Poulantzas é similar à de Guérin: o fascismo é um fenômeno que ascende ao poder tendo como base de apoio de massa a pequena burguesia e, uma vez no poder, realiza os interesses do grande capital monopolista. O diferencial reside na análise do Estado, de encontro a teses economicistas sobre o imperialismo (da III Internacional).

Iniciemos pela definição do Estado na fase do capitalismo monopolista como intervencionista, implica em afirmar que nessa fase o Estado muda de natureza, deixa de ser o Estado liberal da fase concorrencial e passa a ser um Estado intervencionista. Por certo, Poulantzas ressalta que, historicamente, nunca existiu capitalismo sem intervenção do Estado, não obstante, na sua fase superior, o Estado é mais intervencionista, desempenha novas funções, que abarcam a presença do Estado no próprio aparelho econômico-produtivo. A ideia central é a seguinte: na etapa monopolista, o papel do Estado se expande, e na fase de transição para o capitalismo monopolista o Estado pode assumir a forma de um estado de exceção: bonapartista, ditatorial ou fascista. Após a fase de transição, no pós-guerra, o papel intervencionista do Estado diminui, continua sendo importante, no entanto recua em comparação ao intervencionismo da fase de transição.

O estudo é sobre a forma fascista (não sobre o estado de exceção em geral) e o primeiro registro a ser feito diz respeito à definição leninista do imperialismo como etapa superior do capitalismo. Isto é, o imperialismo não se reduz ao domínio político dos Estados dominantes sobre os Estados dominados, nem pode ser compreendido meramente como solução encontrada pelos capitalistas para as limitações de consumo e realização do valor nos países dominantes, por meio da conquista de mercados externos. Na visão leninista, o imperialismo é o capitalismo na sua fase monopolista, mas Poulantzas quer ir além dessa definição, centrada no econômico, e analisar a dimensão política do imperialismo, seja na fase de transição para a hegemonia do capital monopolista, na qual está inserida o fenômeno do fascismo, seja superada a fase de transição. 
Ademais, cabe destacar que a etapa do capitalismo monopolista/imperialismo é engendrada pelo desenvolvimento desigual e combinado do capitalismo em escala mundial, a "cadeia imperialista", hierárquica, vai ser conformada nesse processo, e os países atrasados - como Alemanha e Itália - constituem, na visão de Poulantzas, elos débeis da cadeia, devemos dizer, os elos fracos do andar de cima da cadeia, porque no andar de baixo existem elos muito mais fracos. Por sua vez, o atraso dos dois países com relação ao desenvolvimento do capitalismo em âmbito mundial define o campo de possibilidades, com efeitos sobre a esfera política, no sentido da forma que o papel mais intervencionista do Estado assumirá.

Teoricamente, uma distinção importante é a entre tipo de Estado, forma de Estado e regime político. O estado fascista pertence ao tipo capitalista de Estado (o fenômeno é capitalista, não existiu antes), a forma de estado de tipo capitalista pode variar entre o estado democrático-liberal e/ou um estado de exceção. À forma de estado corresponde o regime político, isto é, em um estado democrático-liberal, existem as denominadas liberdades individuais (asseguradas pela consagração formal dos direitos civis e políticos), no estado de exceção essas são suprimidas ou bastante restringidas. É no âmbito do regime político que vai ocorrendo o processo de disseminação do fascismo, quer dizer, de início, o princípio liberal da divisão dos poderes/constitucionalismo é conservado, porém a forma liberal vai se deteriorando à medida que o fascismo conquista cada vez mais espaço no aparelho de Estado (em especial, nos ramos repressivos).

O Estado fascista, como apontado, é a forma assumida na fase de transição para o capitalismo monopolista, sendo o papel econômico, político e ideológico do Estado redobrado, devido ao papel particular que o Estado desempenha em fases de transição. Quer dizer, assim como o Estado desempenha um papel decisivo na transição de um modo de produção a outro (do feudalismo para o capitalismo), o Estado fascista assume proeminência no processo de transição para a consolidação do capitalismo monopolista. Desse modo, temos duas dimensões: o Estado na fase monopolista é um Estado intervencionista; e o Estado fascista é um Estado intervencionista reforçado, pois inserido na fase de transição para o domínio do capitalismo monopolista na Itália e na Alemanha.

Isso não significa que o fascismo só emerge nessa fase de transição, pois o definitivo não é a fase, e sim a dimensão da crise do capitalismo (econômica, política e ideológica) que engendra o fascismo. Fenômeno que não deve ser entendido como uma necessidade histórica, no caso dos 
Estados Unidos, por exemplo, há mais intervenção estatal com o New Deal, sem fascismo. O intervencionismo pronunciado não se reveste necessariamente da forma fascista, para se compreender o porquê da ascensão do fascismo na Alemanha e na Itália é preciso estudar a história do desenvolvimento capitalista nesses países e a luta política que o caracteriza.

Por fim, Poulantzas abraça a ideia de Estado integral de Gramsci, também de Althusser, com a ideia de Aparelhos Ideológicos de Estado (AIE), embora, ele faça críticas ao formalismo de Althusser. A ideia de Estado integral é conhecida, consiste em conceber Estado capitalista para além do aparelho repressivo-administrativo, estendendo as funções de dominação política para uma série de organizações, públicas e privadas, com destaque para as de inculcação ideológica. Assim sendo, o intervencionismo estatal englobaria organizações como igrejas, escolas, sindicatos, partidos, aparelhos de informação. Em um Estado intervencionista "normal" (que conserva formalmente a forma liberal-democrática), essas organizações gozam de autonomia relativa com relação ao Estado entendido como aparelho repressor. Essa autonomia relativa é que será destruída ou fortemente abalada em todo estado de exceção, no fascismo, em um processo de reorganização ideológico marcadamente violento.

No entanto, não se trata meramente da supressão da autonomia relativa dos AIE pelos ramos repressivos do Estado, nos dois casos analisados, e paradigmáticos, a ideologia fascista penetrou antes no sistema estatal, por meio da atuação de aparelhos ideológicos (notadamente, o partido político), conquistando os ramos repressivos e, depois, com o Estado fascista estabelecido, este subordina o fascismo como movimento. Poulantzas destaca a importância da reorganização ideológica, ou para falar em linguagem atual, a importância conferida à guerra cultural. Neste terreno, o autor discorrerá sobre a tríade Partido-Família-Propaganda como o coração do fenômeno do fascismo, sendo a exaltação da família, em especial da mulher como mãe, peça-chave da propaganda ideológica. Para concluir, cabe enfatizar que, para o autor, o movimento fascista jamais teria chegado ao poder sem antes adentrar com força no aparelho repressivo de Estado.

Duas obras imprescindíveis à reflexão sobre o fascismo.

Recebido em: 22 de novembro de 2021 Aceito em: 28 de dezembro de 2021 